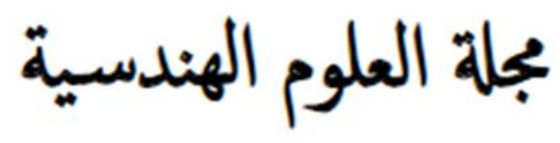

\title{
Effect of Using EVA as Partial Replacement for Coarse Aggregates on Concrete Properties
}

\author{
Moatasim Attaelmanan Alnour Mustafa ${ }^{1}$, Mohammed Izzeldeen Mansour Ibrahim ${ }^{1, *}$, Mohammed Tawfeeg \\ Mohammed Alradey ${ }^{1}$ and Mohammed Altayeb Berier Alsheikh ${ }^{1}$ \\ 1 Civil Engineering Department, Karary University, Omdurman, Sudan \\ * Corresponding author: Mohammed Izzeldeen Mansour Ibrahim (e-mail: m.izzeldeen287@gmail.com). \\ Article history: Received 14 March 2020, Received in revised form 4 November 2020, Accepted 11 November 2020
}

\begin{abstract}
Ethylene-vinyl acetate (EVA), is the copolymer of ethylene and vinyl acetate. The weight percent of vinyl acetate usually varies from 10 to $40 \%$, with the residuum being ethylene, also EVA is an elastomeric polymer that makes materials which are (rubber-like) in fineness and flexibility. In this study, EVA waste was used in the concrete mix instead of different percentages of coarse aggregates $(5 \%, 8 \%, 10 \%, 12 \%)$ by volume. The concrete slump test was performed to measure the workability of freshly made concrete. The compression test was performed on all samples at 7 and 28 days. The results were compared with the standard mixture. It was concluded that EVA was a suitable material to replace coarse aggregates. Accordingly, the results of these experiments indicate that not only EVA can be noticed as aggregate in concrete, but also it will have more advantages in lightweight concrete than normal concrete. Using of EVA concrete shows decrease in slump for further replacement without compromising on strength. The best replacing ratio was $5 \%$ of aggregate.
\end{abstract}

Keywords: EVA, Coarse Aggregates, Lightweight Concrete, Slump, Compressive Strength.

\section{INTRODUCTION}

The use of plastic materials has been growing all over the world in packing, automotive and manufacturing applications. This results in a great generation of urban and manufacturing waste that can be stored or discarded. Due to the low density of plastics, storage or organization in landfills implies the availability of large surface areas. The elimination of plastics can be done by incineration, although, as the production of plastics involves the use of potentially harmful chemicals, the ashes produced may not always be passable in a landfill because of their potentiality to cause groundwater and soil pollution due to leachate carrying heavy metals. These problems have increased the use of recycled thermoplastics such as polyethylene, polypropylene and polyamide, which can be melted for recycling in the plastic industry. Moreover, the thermosetting plastic, such as (EVA) used by the footgear industry, cannot be melted through heat [1].
One way to using recycled plastics is their incorporation into (LWC). When selecting suitable combinations of filler and binder thus formed building material can be used not only in new construction, but also in reconstruction and renovation of existing buildings [2].

(EVA) is a co-polymer made from two different monomers: Ethylene monomer and Vinyl acetate monomer. In a foam state, EVA has characteristics like rubber, making it useful where cushioning is important such as in midsoles, sock liners, and unit soles in footwear.

In EVA, the relative amount of vinyl acetate to ethylene effects polymer characteristics.

Higher vinyl acetate content resort to make the polymer smoother and more rubbery, while lower vinyl acetate content tends to make the polymer harder and more crystalline, Fig.1. illustrate the molecular formula of EVA [3].

This material is bright and has good properties as an inhibitor, See Fig.2. low heat and high durability, it is easy to work on, conductive and 
weld-proof, and has high body and flexibility and high load resistance Impact, high viscosity, anti-effort in cracks, high partial weight, non-leakage Water, radiation resistance, and UV. The more the content of vinyl acetate changes, the less Crystals of different properties of polymeric ethylene acetate are based mainly on content or percentage. In the lower level of vinyl acetate, the vinyl acetate has a heat-related skin with properties Similar to low density polyethylene ASTM 40-960 depending on $150 \mathrm{~kg} / \mathrm{m}^{3}$ minimum density Clear, bright materials, Well-durable, Resistance of stresses to cracks, Lightweight, High viscosity, High partial weight, Easy to form, Leak proof and High resistance to UV radiation and radiation [4].

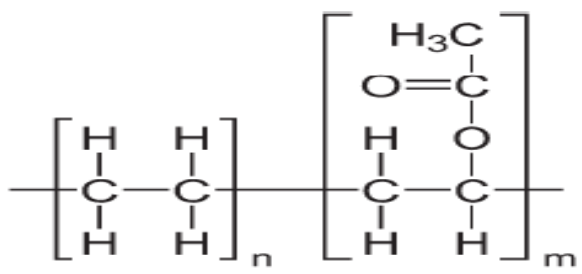

Fig.1.The molecular formula of EVA

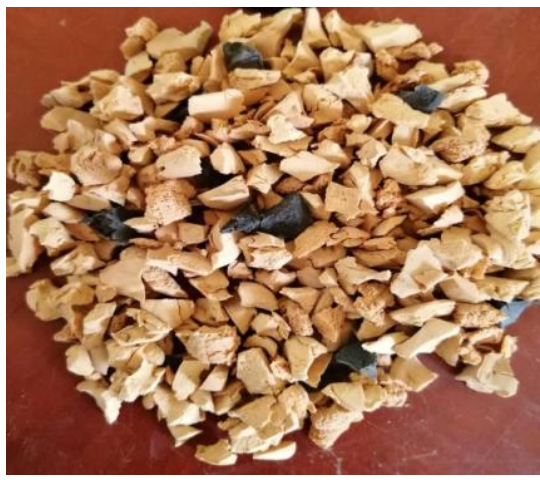

Fig.2.EVA Sample

The low density of the mixture is achieved due to the use of lightweight aggregates which produces specific characteristics such as low density, ranging from $300 \mathrm{~kg} / \mathrm{m}^{3}$ to $1800 \mathrm{~kg} / \mathrm{m}^{3}$ and compressive strength, ranging from $0.3 \mathrm{~N} / \mathrm{mm}^{2}$ to $40 \mathrm{~N} / \mathrm{mm}^{2}$.

The coarse and fine aggregates are considered lightweight when their density is less than 1120 $\mathrm{kg} / \mathrm{m}^{3}$ and greater than $880 \mathrm{~kg} / \mathrm{m}^{3}$, respectively [5].

It is known that such wastes have great potential to be used as (LWC), in substitution of natural aggregates in the production of alternative products. It is a waste with low density, large deformation capacity, and good vocal and thermal properties, stable, inert and non-susceptible to mushroom [6].

The use of (LWC) permits greater design flexibility and essential cost savings, reducing dead load, improved cyclic loading structural response, longer spans, thinner sections, smaller size structural members, less reinforcing steel, and lower foundation costs, although, to produce artificial (LWC) is necessary high consumption of energy.

Plastics waste, as EVA has been used with relative success to produces concrete, (LWC) and components of construction.

The use of these materials as aggregate to production of concrete has economical and ecological impact due large amount of waste made annually [7].

The purpose of this study is to evaluate the performance of concrete with (EVA) recycled aggregate replacing conventional coarse aggregate in the production of lightweight concrete.

Previous study [8] Displayed that it is possible to use polymer waste in a new product with efficient acoustic and thermal performance compared to conventional lightweight subfloors.

Study [9] analyzed the efficiency of micronized EVA composite subfloors in test specimens of 3, 5 and $7 \mathrm{~cm}$ thickness and three polymer addition contents. Samples with 50\% micronized EVA displayed better impact insulation efficiency with $\Delta \mathrm{L}^{\prime n T}, \mathrm{w} 23 \mathrm{~dB}$.

Research [10] proposes the use of EVA waste and rice husk in subfloors to lessen impact noise, substituting natural fine aggregates in the contents of 25,50 and $75 \%$. The results displaced that the use of both natural and artificial waste can represent gains in the efficiency of effect noise acoustic insulation for subfloors when used in larger proportions.

In research [11], piassava fibers were used as reinforcement of (LWC) containing $4 \%$ and $6 \%$ of EVA, with the goal of improving the flexural strength of the material. The experimental results demonstrate that the addition of EVA decreases 
the density and flexural strength of the concrete in proportion to the amount of addition, but a recovery resistance is got when the piassava fibers are added in amounts of 1 to $2 \%$ by volume.

The test results were carried out in previous study [12] showed that the average compressive strength at 28 days of the original EVA block was $1.2 \mathrm{~N} / \mathrm{mm}^{2}$, whereas the block EVAr70 was 2.2 $\mathrm{N} / \mathrm{mm}^{2}$ and the block EVAr 50 was $1.7 \mathrm{~N} / \mathrm{mm}^{2}$. Thence, there was an $83 \%$ increase in the compressive strength on the block $\operatorname{EVAr}_{70}$ and $44 \%$ on the block EVAr50. It was also observed there was no significant difference among the weights of all the blocks produced. Thus, it appears that the EVAr aggregate impacted more in the compressive strength than in the mass of the blocks. So, the recyclability of the EVA block appears viable.

Previous study [13] specified that mixes prepared with aggregates that are basic in nature, i.e. with higher calcium content, show better bonding with both neat bitumen and EVA-modified bitumen compared with acidic aggregates, i.e. aggregates with higher silica content.

\section{MATERIAL AND METHODS}

\subsection{Cement}

The cement used was Ordinary Portland cement (42.5 Grade) produced by Sakhr Al Sudan Company conforming to BS EN 197-1 [14]. The characterization of the cement used is shown in table I.

\subsection{Fine Aggregates (FA)}

The sand used for experimental program was locally. The sand was first sieved through 4.75 $\mathrm{mm}$ sieve to remove any particles greater than $4.75 \mathrm{~mm}$. The fine aggregates were tested as per British Standard Specification BS EN 12620:2002. The specific gravity was found to be 2.47 , water

TABLE I: CHARACTERIZATION OF THE CEMENT

\begin{tabular}{c|c}
\hline \hline Properties & Results \\
\hline Initial setting time & $140 \mathrm{~min}$ \\
\hline Final setting time & $245 \mathrm{~min}$ \\
\hline Compressive Strength & $42.31 \mathrm{~N} / \mathrm{mm}^{2}$ \\
\hline \hline
\end{tabular}

Absorption 1.8\%.

\subsection{Coarse Aggregates ( $C A$ )}

The natural coarse aggregate used for this study was of $20 \mathrm{~mm}$ maximum size. It is conforming to BS EN 12620:2002. Specific gravity was found to Be 2.65, water Absorption $0.7 \%$ and voids ratio $35.21 \%$. It was retrieved from a local coarse.

\subsection{EVA Aggregates}

EVA coarse aggregate used for this study was of $9.5 \mathrm{~mm}$ maximum size characterized by small color particles (Fig.2.) which are obtained from cutting off expanded sheet waste used to produce insoles and innersoles of shoes. Specific gravity was found to be 0.45 .

\subsection{Mix Design}

Mix design is done as per BS 8500-2 method [15].The blends used in this research were designed to achieve a specific compressive strength of $30 \mathrm{~N} / \mathrm{mm}^{2}$ in 28 days. Eva material has been added as a function of the aggregate displacement volume and the specific weight of the Eva material, the calculation was done as follows:

Eva weight $=$ density of Eva $\mathrm{x}$ volume of aggregate displaced. In order to study the mechanical properties of EVA waste concrete, five mix proportions were made.

The percentage replacements of aggregates by industrial EVA waste were $5 \%, 8 \%, 10 \%$ and $12 \%$. This was done to determine the proportion that would give the most favorable result. The $0 \%$ replacement was to serve as control for other sample which is finally used for the comparison. The mix proportions studied for the EVA waste concrete are totally 5 proportions as shown in Table II.

\section{Mix Design Method}

5 concrete mixes were prepared with various percentages of EVA waste. The details of various mix proportions for different replacement levels of Aggregate by EVA waste.

The aggregate dry density used was 1668.43 $\mathrm{kg} / \mathrm{m}^{3}$ and the maximum aggregate size use in all mixes was $20 \mathrm{~mm}$ using standard cubes moulds $\left(150^{*} 150^{*} 150\right) \mathrm{mm}, 6$ cubes representing each ratio, were casted and tested at age 7 and 28 days. 


\begin{tabular}{c|c|c|c|c|c}
\hline \hline Mix & $0 \%$ & $5 \%$ & $8 \%$ & $10 \%$ & $12 \%$ \\
\hline $\begin{array}{c}\text { Free } \\
\text { water } \\
(\mathrm{kg} / \mathrm{m} 3)\end{array}$ & 195 & 195 & 195 & 195 & 195 \\
\hline $\begin{array}{c}\text { Cement } \\
(\mathrm{kg} / \mathrm{m} 3)\end{array}$ & 405 & 405 & 405 & 405 & 405 \\
\hline $\begin{array}{c}\mathrm{FA} \\
(\mathrm{kg} / \mathrm{m} 3)\end{array}$ & 840 & 840 & 840 & 840 & 840 \\
\hline $\begin{array}{c}\mathrm{CA} \\
(\mathrm{kg} / \mathrm{m} 3)\end{array}$ & 950 & 902.5 & 873.75 & 855 & 837.5 \\
\hline $\begin{array}{c}\mathrm{EVA} \\
(\mathrm{kg} / \mathrm{m} 3)\end{array}$ & - & 14.4 & 25.31 & 28.69 & 39.94 \\
\hline \hline
\end{tabular}

\section{RESULTS AND DISCUSSION}

\subsection{Slump}

Slump test was carried out on the five mixes. It was realized that the slump decreases when increasing the percentage ratio of the EVA waste in the mix as shown in Fig.3.

\subsection{Density}

In table III and Fig.4. Observe the values of average density for different propositions from EVA waste, the lowest density values belong to concrete with the highest replacement level of EVA. The mixtures $12 \%$ EVA can be classified as lightweight concrete.

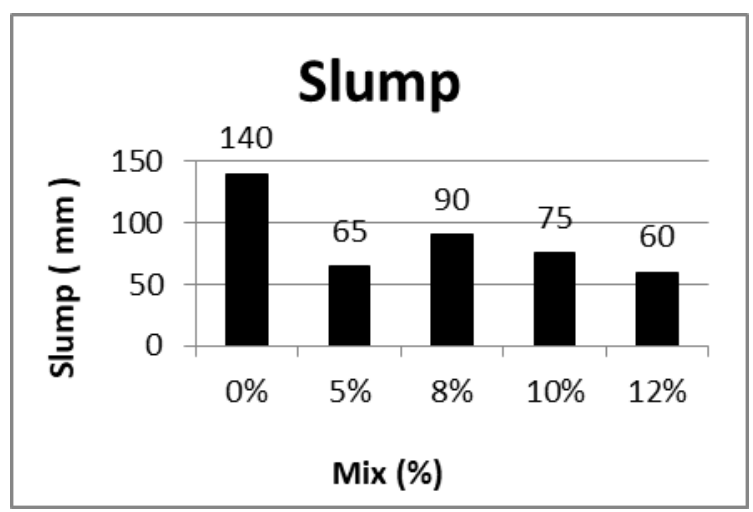

Fig.3. Slump

TABLE III: RESULTS OF AVERAGE DENSITY AT 7 AND 28 DAYS

\begin{tabular}{c|c|c|c|c}
\hline \hline Mix & $\begin{array}{c}7 \text { days } \\
\text { density } \\
(\mathrm{kg} / \mathrm{m} 3)\end{array}$ & $\begin{array}{c}\text { Change } \\
\text { percentage } \\
(\%)\end{array}$ & $\begin{array}{c}28 \text { days } \\
\text { density } \\
(\mathrm{kg} / \mathrm{m} 3)\end{array}$ & $\begin{array}{c}\text { Change } \\
\text { percentage } \\
(\%)\end{array}$ \\
\hline $0 \%$ & 2429.62 & - & 2436.53 & - \\
\hline $5 \%$ & 2378.96 & 2.08 & 2396.5 & 1.64 \\
\hline $8 \%$ & 2326.1 & 4.26 & 2333.5 & 4.22 \\
\hline $10 \%$ & 2322.45 & 4.41 & 2321.3 & 4.72 \\
\hline $12 \%$ & 2264.29 & 6.8 & 2277.09 & 6.53 \\
\hline \hline
\end{tabular}

\subsection{Compressive Strength}

The compressive strength test was carried out on $15 \mathrm{~cm}$ cubic specimens, Table IV and Table V gives the results of compressive strength at 7 days and 28 days. Fig.5, Fig.6. and Fig.7. shows compressive strengths comparison of all concrete mixes.

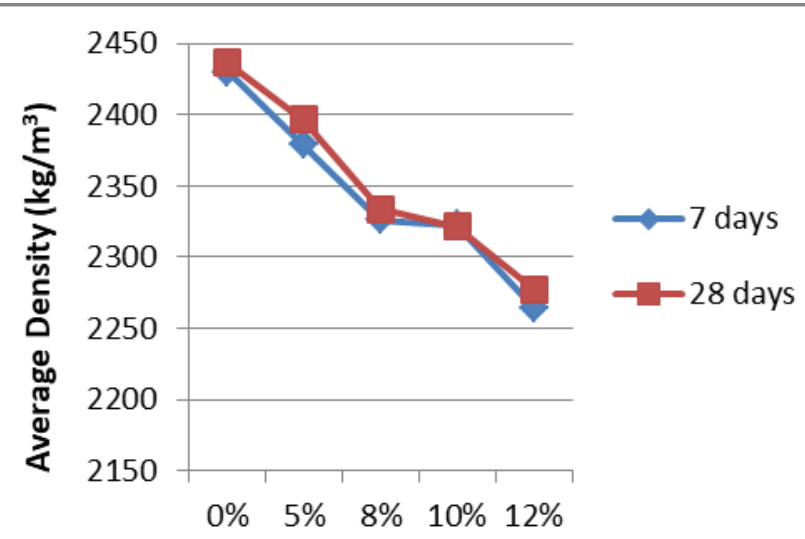

EVA Percentage (\%)

Fig.4. Relation between percentage of EVA and Average Density of concrete at ages of 7 and 28 days

According to these results, compressive strength of EVA aggregate concretes is lower than natural aggregate concretes as can be seen in Fig.5, which can be due to the lower density of EVA concretes.

\begin{tabular}{c|c|c}
\multicolumn{3}{c}{ TABLE IV: RESULTS OF AVERAGE COMPRESSIVE STRENGTH AT 7 DAYS } \\
\hline \hline Mix & $\begin{array}{c}7 \text { days Compressive Strength } \\
(\mathrm{N} / \mathrm{mm} 2)\end{array}$ & $\begin{array}{c}\text { Change percentage } \\
(\%)\end{array}$ \\
\hline $0 \%$ & 34.76 & - \\
\hline $5 \%$ & 31.94 & $8.11 \%$ \\
\hline $8 \%$ & 25.94 & $25.37 \%$ \\
\hline $10 \%$ & 25.74 & $25.94 \%$ \\
\hline $12 \%$ & 25.20 & $27.5 \%$ \\
\hline \hline
\end{tabular}

TABLE V: RESULTS OF AVERAGE COMPRESSIVE STRENGTH AT 28 DAYS

\begin{tabular}{c|c|c}
\hline \hline Mix & $\begin{array}{c}28 \text { days Compressive } \\
\text { Strength }(\mathrm{N} / \mathrm{mm} 2)\end{array}$ & $\begin{array}{c}\text { Change percentage } \\
(\%)\end{array}$ \\
\hline $0 \%$ & 46.57 & - \\
\hline $5 \%$ & 42.05 & $9.7 \%$ \\
\hline $8 \%$ & 33.87 & $27.27 \%$ \\
\hline $10 \%$ & 32.43 & $30.36 \%$ \\
\hline $12 \%$ & 31.7 & $31.93 \%$ \\
\hline \hline
\end{tabular}

\section{CONCLUSIONS}

This paper demonstrates that it is possible to use solid wastes of the footwear industry and the construction industry as aggregate for the production of conventional and lightweight concrete. Based on the results, the following conclusions can be drawn:

1. The density of recycled concrete was reduced. The lowest density values belong to concrete with the highest replacement level of EVA.

2. It was observed that the workability was reduced by increasing the amount of the EVA in the concrete mixes; the highest value of workability was achieved at $8 \%$ EVA concrete mix. 


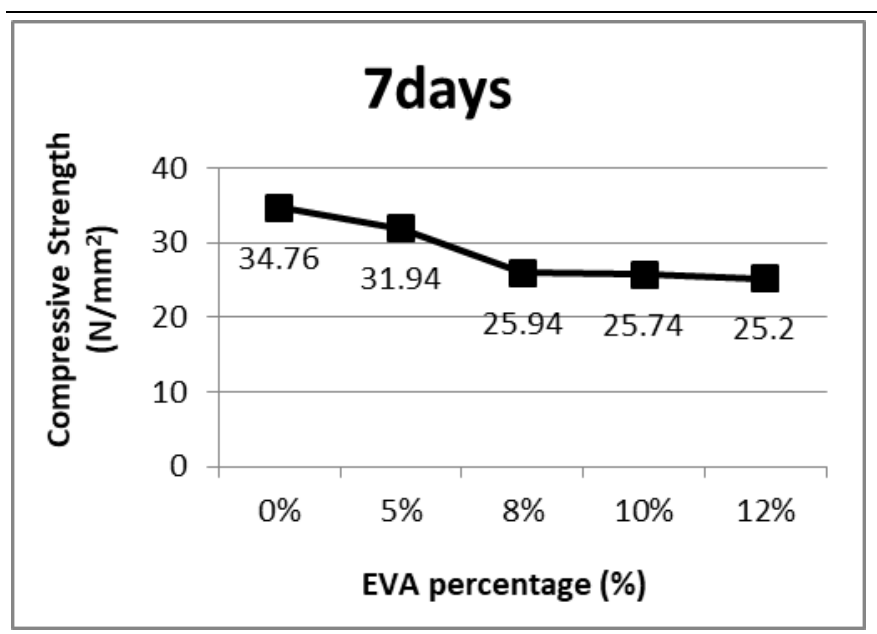

Fig.5. compressive strength at 7 days
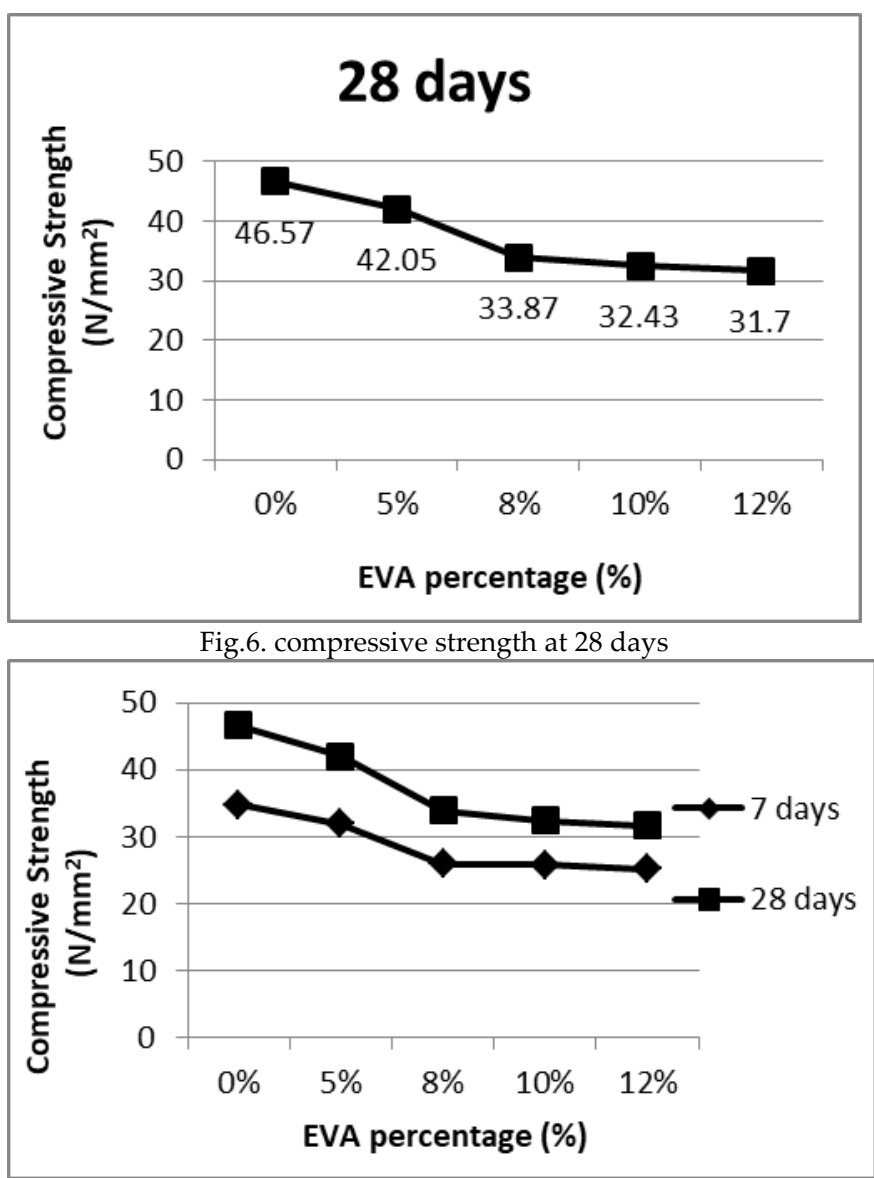

Fig.7. compressive strength at 7 and 28 days

3. Results of the experiments which are carried out on hardened concrete, indicate that $5 \%$ EVA concrete mix achieved higher values of compressive strength compared to other replacement ratio where it was $9.7 \%$ less resistant than the standard mix and it was the most suitable ratio for use.

4. It was observed that all EVA replacement ratios $(5 \%, 8 \%, 10 \%, 12 \%)$ achieved the compressive strength higher than characteristic compressive strength which is equal to $30 \mathrm{~N} / \mathrm{mm}^{2}$ in 28 days.

5. Recycling EVA as aggregate in concrete not only improves mechanical properties of concrete, but also helps the surrounding environment to be protected against its severe deposit problems.

\section{ACKNOWLEDGMENT}

History of all great is to witness that no great work was ever done without either the active or passive support a person's surrounding and one's close quarters. Thus it is not hard to conclude how active assistance from seniors. Could prohibitively impact the execution of a project. We highly thankful to our learned faculty Dr. Moatasim Attaelmanan for his active guidance throughout the completion of project.

Last but not the least, we would also want extend our appreciation to those who could not be mentioned here but here well played their role to inspire the curtain.

\section{REFERENCES}

[6] A. B. De Melo and E. P. Silva, "Bloques de hormigón ligero con áridos reciclados de EVA: Una contribución a la eficiencia térmica de paredes exteriores de edificios," Mater. Constr., vol. 63, no. 312, pp. 479-495, 2013.

E. Q. R. Santiago, P. R. L. Lima, M. B. Leite, and R. D. Toledo Filho, "Mechanical behavior of recycled lightweight concrete using EVA waste and CDW under moderate temperature," Rev. IBRACON Estruturas e Mater., vol. 2, no. 3, pp. 211-221, 2009.

[8] F. D. Alessandro, F. Asdrubali, and G. Baldinelli, "Multi-parametric characterization of a sustainable lightweight concrete containing polymers derived from electric wires," Constr. Build. Mater., vol. 68, pp. 277-284, 2014.

[9] L. R. Brancher, M. F. D. O. Nunes, A. M. C. Grisa, D. T. Pagnussat, and M. Zeni, "Acoustic behavior of subfloor lightweight mortars containing micronized poly (ethylene vinyl acetate) (EVA)," Materials (Basel)., vol. 9, no. 1, pp. $1-9,2016$.

[10] J. K. Borges, F. Pacheco, B. Tutikian, and M. F. de Oliveira, "An experimental study on the use of waste aggregate for acoustic attenuation: EVA and rice husk composites for 
impact noise reduction," Constr. Build. Mater., vol. 161, pp. 501-508, 2018.

[11] T. F. de Souza, P. R. L. Lima, F. D. R. Amado, R. de A. A. Alvim, F. M. R. dos Santos, and D. D. S. Nunes, "EVA Lightweight Concrete Reinforced with Piassava Fiber," Appl. Mech. Mater., vol. 864, pp. 296-301, 2017.

[12] F. A. Meira, M. Da Paz Medeiros Fernandes, A. B. De Melo, and E. P. Da Silva, "Study of EVA blocks waste recyclability," in Key Engineering Materials, 2012, vol. 517, pp. 646-652.

[13] M. Singh, P. Kumar, and M. R. Maurya, "Effect of aggregate types on the performance of neat and EVA-modified asphalt mixtures," Int. J. Pavement Eng., vol. 15, no. 2, pp. 163-173, 2014.

[14] British Standards Institution,BS EN 179-1 :2000, Cement-Part 1 : Composition, specifications and conformity criteria for common cements.

BS 8500-2: 2002- Concrete - Complementary British Standard to BS EN 206-1- Part-2 Specifications for constituent materials and concrete : BSI 389 Chiswick High Road London.

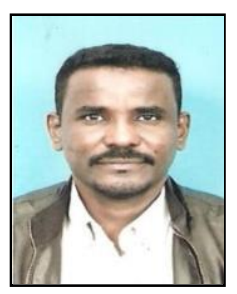

Mustafa, M.A.A. was born in Sudan, on $16^{\text {th }}$ April 1975. In 2011 earned a PHD in Highway Engineering from Northeast forestry University, Harbin, P.R.C. and an MSc in 2003 in the field of structural Engineering from Karary University, Omdurman, Sudan and a BSc in 2000 in Civil Engineering from Karary University, Omdurman, Sudan.

He initially worked as Engineer in the corps of Engineering before joining the Civil Engineering Department, Faculty of Engineering, Karary University (2001) as a full time staff member assuming several posts there.

He started as a Teaching Assistant then a lecturer of structural engineering, and later Assistant Professor. He became the Civil Engineering program coordinator in 2013 up to date. He has participated in many scientific conferences in Sudan and abroad and has several publications related to Highway Engineering and building materials ( $2^{\text {nd }}$ conference of Civil Engineering in Sudan, Sudan 2018). Current research interests include building materials, soil mechanics and bitumen mixtures.

Dr. Mustafa has been involved in several committees of preparation the course content of civil engineering to some Universities and Colleges.

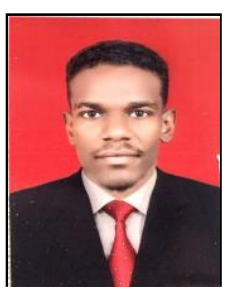

Mohammed Izzeldeen Mansour Ibrahim. Was born in Sudan, on $28^{\text {th }}$ July 1994.

In December 2018 earned a BSc in Civil Engineering Department of Structure from Karary University, Omdurman, Sudan.

Mr. Ibrahim is a member of the Sudanese Engineering Council (SEC).

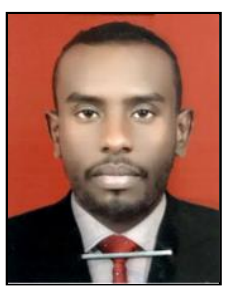

Mohammed Tawfeeg Mohammed Alradey. Was born in Sudan, on $3^{\text {th }}$ March 1993.

In 2014 earned a Dip.Sc in Civil Engineering Department of Structure from Sudan University of Science and Technology, Khartoum, Sudan and a BSc in December 2018 in Civil Engineering Department of Structure from Karary University, Omdurman, Sudan.

He worked as a Structural Engineer at Abu Garga Contracting Co. Ltd (March 2014 - up to date).

Mr. Alradey is a member of the Sudanese Engineering Council (SEC).

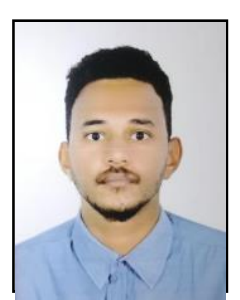

Mohammed Altayeb Berier Alsheikh. Was born in Saudi Arabia, on $2^{\text {th }}$ May 1996.

In December 2018 earned a BSc in Civil Engineering Department of Structure from Karary University, Omdurman, Sudan.

He worked as a Structural Engineer at Rabih Elnor Engineering Contracting Co. Ltd (November 2019 up to date). 